\title{
Prospective audit of mucosal biopsy specimens of the gastrointestinal tract
}

\author{
P M Stephenson, P J Gallagher
}

\begin{abstract}
Aims-To determine why mucosal biopsy specimens of the gastrointestinal tract were taken and whether they were justified on clinical or pathological grounds.

Methods-A prospective audit of 190 consecutive biopsy specimens received in a university hospital histology department over six weeks.

Results-The 31 separate presenting symptoms included diarrhoea (34\%), abdominal pain (16\%) and rectal bleeding $(15 \%)$. In $41 \%(78 / 190)$ the histology was normal, $28 \%$ (53/190) showed inflammatory changes and $11 \%(21 / 190)$ carcinoma. A clear justification for the procedure was identified in over $90 \%$ (171/ $190)$ of patients. In $36 \%(68 / 190)$ there was a change in patient management on receipt of biopsy reports and further investigations were ordered in $29 \%(55 / 190)$. The mean time taken to report biopsy specimens was $4 \cdot 7$ working days and there was no difference between the reporting time of a pathologist compared with a consultant or a trainee.

Conclusions-There is no evidence that mucosal biopsy specimens are taken unnecessarily.

( $f$ Clin Pathol 1995;48:936-938)
\end{abstract}

Keywords: Audit, mucosal biopsy specimens, patient management.

For the past 10 years, mucosal biopsy specimens of the gastrointestinal tract have made up about $15 \%$ of our surgical histology workload and in absolute numbers have increased each year. Further increases are likely as general practitioners expect increased access to endoscopic services and the numbers of colonoscopies rises to levels recommended by specialist advisory groups. ${ }^{1}$ Pathologists are rightly concerned about the accuracy and consistency with which these biopsy specimens are reported, ${ }^{23}$ but we are more concerned about

Table 1 Definitions used to asses changes in treatment or management

\begin{tabular}{ll}
\hline Degree of change & Definition \\
\hline No change & $\begin{array}{l}\text { Same drugs } \\
\text { Same treatment plan } \\
\text { Continued investigation of current problem following unhelpful biopsy } \\
\text { report }\end{array}$ \\
Minor changes in dose of same drug \\
$\begin{array}{l}\text { Different class of drug but treatment based on same diagnosis as before } \\
\text { biopsy }\end{array}$ \\
$\begin{array}{l}\text { Variation in treatment but based on same diagnosis as before biopsy report, } \\
\text { but excluding invasive or operative procedures } \\
\text { Invasive procedure on operation after receipt of biopsy report } \\
\text { Any drug or treatment change based on a new or different diagnosis }\end{array}$ \\
\hline
\end{tabular}

the clinical value of the biopsy itself. Before this study began we had the impression that many were histologically normal and sometimes questioned their value, both in terms of patient management and the proper use of laboratory services. After a short pilot investigation we designed a prospective clinicopathological study to test our hypothesis that a significant number of mucosal biopsy specimens are unnecessary or, at least, contribute little to patient management.

\section{Methods}

All mucosal biopsy specimens from the gastrointestinal tract received in the Southampton University Hospital histopathology laboratory over a consecutive six week period were studied. Oral, dental, pharyngeal, and perianal biopsy specimens were excluded.

Eighty items of clinical or pathological information were recorded for each case, coded on a proforma, transferred onto tape, and analysed by SPSS-X. The analyses were mainly descriptive using frequency tables and histograms; some cross tabulations were also performed and some new summary variables were created to express detailed data more intelligibly.

The information from the histology request cards and the biopsy reports was largely factual and could be transferred into numerical data with little difficulty. All histology was reviewed and where necessary discussed with the pathologist who originally reported the case. The clinical records were examined no less than four weeks after the biopsy. The information extracted included details of major symptoms, their severity and duration, past illnesses, treatment at the time of biopsy, and further investigations ordered after the biopsy report was received. Changes in drug treatment and patterns of investigation and management that were related to the receipt of the biopsy report were graded using the guidelines summarised in table 1. A combination of histological and clinical information was used to define justifications for the biopsy procedure. In a small number of cases these were discussed with the responsible clinicians.

\section{Results}

The median age of the 190 patients studied was 58 years (range eight to 95 years) and the sex ratio was exactly equal. The biopsies were performed at five separate hospitals and only one health centre. Patients were seen by 29 different accredited specialists; two gastroenterologists accounted for $35 \%$ of all cases. 
Table 2 Time taken to report mucosal biopsy specimens by consultant and junior medical staff (figures refer to \% of biopsies reported)

\begin{tabular}{lll}
\hline $\begin{array}{l}\text { Reporting time } \\
\text { (in working days) }\end{array}$ & $\begin{array}{l}\text { Consultant alone } \\
\text { (\%) }\end{array}$ & $\begin{array}{l}\text { Consultant plus } \\
\text { junior (\%) }\end{array}$ \\
\hline $1-3$ & $22 \cdot 7$ & $26 \cdot 8$ \\
$4-6$ & $57 \cdot 7$ & $61 \cdot 0$ \\
$7-9$ & $18 \cdot 6$ & $11 \cdot 0$ \\
$10+$ & $1 \cdot 0$ & $1 \cdot 2$ \\
\hline
\end{tabular}

No significant differences were found for the reporting times of the two categories.

Seven specialists submitted one biopsy specimen only. Over the six weeks of the study the biopsy specimens were examined by five consultants and nine trainee pathologists.

\section{HISTOPATHOLOGY}

There were $73(38.4 \%)$ rectal, $38(20 \%)$ gastric and $38(20 \%)$ colonic, $24(12 \cdot 6 \%)$ small intestinal, and $17(9 \%)$ oesophageal biopsy specimens; $47 \%$ (89/190) of all patients had had a previous histology report issued by the department.

There were 49 different histopathological diagnoses. In $41 \%(78 / 190)$ the histology was normal, carcinoma was diagnosed in $11 \%$ (21/ $190)$ and inflammation or inflammatory bowel disease in $26 \%(50 / 190)$. Of the biopsy reports, $42 \%(80 / 190)$ had no histological detail apart from a diagnosis. In the others, 33 different features were described as present or absent. On review, there were no major disagreements with the original diagnosis and minor disagreements in only two of the 190 cases.

The average time between the arrival of the specimen in the laboratory and the dispatch of the signed report was 4.7 working days (SD 1.9 , range one to 14 working days); $29 \%$ (55/ $190)$ of reports took more than one working week. Of the urgent requests, $30 \%(57 / 190)$ were dispatched within three and $80 \%$ (152/ 190) within four working days. There was no correlation between either the site of the biopsy or the pathological diagnosis and the total reporting time. Reports produced jointly by a consultant and a member of the junior staff were issued in almost exactly the same time as those by a consultant alone (table 2 ).

Table 3 Changes in patient management after biopsy report received

\begin{tabular}{lllc}
\hline & \multicolumn{3}{l}{ Changes in management } \\
\cline { 2 - 4 } Histological diagnosis & No change (\%) & Minor change (\%) & Major change (\%) \\
\hline Normal histology & 82.9 & $12 \cdot 2$ & 4.9 \\
Inflammation & $42 \cdot 3$ & $11 \cdot 5$ & $46 \cdot 2$ \\
Other diagnosis & 56.7 & 13.3 & $30 \cdot 0$ \\
\hline
\end{tabular}

Table 4 fustification for mucosal biopsy

\begin{tabular}{ll}
\hline Clinical or histological justification & No. of cases \\
\hline Firm histological diagnosis & 26 \\
Important diagnosis excluded (for example, malignancy or IBD) & 68 \\
Subsequent change in management & 27 \\
Assess progress of disease & 11 \\
Confirm previous diagnosis & 11 \\
Further line of investigation & 11 \\
No obvious justification & 10 \\
\hline
\end{tabular}

Note: the total number of case records suitable for evaluation was 129 . There were two separate justifications in 55 and three in 12 patients. IBD = inflammatory bowel disease.

\section{CLINICAL FEATURES}

Patients presented with 31 different symptoms, most commonly diarrhoea (34\%) (64/190), abdominal pain (16\%) (30/190) and rectal bleeding (16\%) (30/190). In 37\% a clinical diagnosis had been made before the biopsy. In $67 \%$ (127/ 190) the biopsy was taken in an outpatient clinic, $24 \%(46 / 190)$ on a ward, $8 \%(15 / 190)$ in theatre, and $1 \%$ (two of 190) in general practice.

There was a change in patient management of some kind on receipt of $36 \%(68 / 190)$ of biopsy reports (table 3 ) and $55 \%(37 / 68)$ of these changes involved drug treatment. Further investigations were ordered on receipt of $29 \%$ $(55 / 190)$ of reports, chiefly barium enema (40\%) (76/190) and colonoscopy (29\%) (55/ $190)$. There was no change in management in $82 \%(156 / 190)$ of patients with normal biopsy reports. A firm decision to proceed to surgery was made in $9 \%(17 / 190)$ of patients at the time the biopsy was taken. A further 5\% (10/ 190) of patients were booked for operation when the biopsy result was obtained.

The case records of 129 of the 190 patients were studied. Others were missing or follow up information had not been entered in appropriate or sufficient detail. In all but 10 there was a plausible justification for the biopsy (table 4).

\section{Discussion}

There has been a noticeable increase in the complexity of the work performed in histopathology laboratories in the past 10 to 15 years. In Britain the greater workload arises from increased numbers of specimens being taken from outpatients rather than from hospital patients, and from increased numbers of comparatively straightforward specimens, such as skin biopsy specimens, being taken by general practitioners. ${ }^{4-6}$ Purchasers of health care are expressing doubt about the value of these biopsy specimens although pathologists have emphasised that in a small percentage unexpected and important diagnoses are made.

A recent external audit of our department showed that the full cost of a biopsy with a single haematoxylin and eosin slide was $£ 21$, giving an annual cost of $£ 35000$ for gastrointestinal biopsy specimens. This prospective study has shown that over $90 \%$ of these biopsy specimens could be justified on one or more clinical grounds, despite the fact that $41 \%$ were histologically normal and a specific pathological diagnosis was made in only a quarter of cases. We were surprised that in $36 \%$ of patients there was a change in clinical management when the biopsy report was available and in nearly $30 \%$ further investigations were then requested.

There have been few comparable studies in the past. A retrospective audit of the clinical indications for over 1500 upper gastrointestinal endoscopies in patients over 65 years of age suggested that $72 \%$ were appropriate, $11 \%$ equivocal and $17 \%$ unjustified. ${ }^{7}$ Over one third of the inappropriate endoscopies were for evaluation of peptic symptoms without a full trial of medical treatment. A more recent pro- 
spective study of 107 consecutive patients with dyspepsia suggested that endoscopy was unhelpful unless biopsy specimens were taken routinely. ${ }^{8}$ Without histology the specificity of endoscopy in the diagnosis of chronic gastritis was less than $60 \%$. It has also been suggested that young patients with dyspepsia can be safely managed without a preliminary gastroscopy. ${ }^{9}$

For two separate reasons we found it more difficult to identify unnecessary large intestinal biopsy specimens. Firstly, there is a growing range of clinicopathological indications for flexible colonoscopy, some centres even advocating periodic colonoscopy as a method of screening for large bowel carcinoma. ${ }^{10} \mathrm{Sec}-$ ondly, there are a number of specific disorders which require histology for diagnosis, and the smallest suspicion of these may be construed as a proper indication for colonoscopy and biopsy. These include amyloidosis and microscopic and collagenous colitis. ${ }^{11} 12$ Furthermore, inflammatory bowel disease can only be accurately diagnosed by examining multiple sections of large intestinal biopsy specimens ${ }^{1314}$ and even macroscopically normal bowel can show dysplasia. ${ }^{15} 16$

Our review of the microscopic features showed no serious disagreement with the original histological diagnosis. This is perhaps exceptional as we know that minor errors occur in up to $3 \cdot 4 \%$ of our routine reports ${ }^{17}$ and that after clinicopathological consultation up to $40 \%$ of gastrointestinal histology reports require some modification. ${ }^{18} \mathrm{~A}$ mean reporting time of nearly five days appears excessively long, particularly as mucosal biopsy specimens are relatively easy to process and can often be reported with a single slide containing several strips of sections. Biopsy specimens which clinicians marked urgent were reported much more quickly. The figures shown in table 4 demonstrate that the delay cannot be attributed to the involvement of junior staff in the examination of biopsy specimens. This is a common explanation for slow reporting in teaching hospitals and one that we have identified by auditing our own reports. ${ }^{14}$ Our histopathology laboratory attracts both favourable and unfavourable comments from its users. Slow re- porting of mucosal biopsy specimens has not been identified as a particular problem perhaps because two thirds of biopsy specimens were taken from outpatients who are unlikely to return to clinic within a week. All small biopsy specimens should be reported within two to three days, but a variety of constraints can make this target unrealistic. Laboratories may need to allocate a priority to certain groups of biopsy specimens. Our results suggest that nonurgent mucosal biopsy specimens need no special treatment but that in clinicopathological terms there is ample justification for these procedures.

1 Scott B. Endoscopic demands in the 90s. Gut 1990;31: 125-6.

2 Brown LJR, Smeeton NC, Dixon MF. Assessment of dysplasia in colorectal adenomas: an observer variation and plasia in colorectal adenomas: an observer variation
morphometric study. $₹$ Clin Pathol 1985;38:174-9.

3 Lessells AM, Beck JS, Burnett RA, Howatson SR, Lee FD McLaren KM, et al. Observer variability in the histopathological reporting of abnormal rectal biopsy specimens. F Clin Pathol 1994;47:48-52.

4 Ramsay AD, Gallagher PJ. Local audit of surgical pathology: 18 months experience of peer review based quality assessment in an English teaching hospital. Am $\mathcal{F}$ Surg Patho 1992;16:476-82.

5 Hillan KJ, Johnson CP, Morton R. Effect of general practitioner contract on referral of specimens for histological examination. BMF 1991;303:1180.

6 McWilliam LJ, Knox F, Wilkinson N, Oogarah P. Performance of skin biopsies by general practitioners. $B M \mathcal{F}$ $1991 \cdot 303 \cdot 1177-9$

7 Williams RB, Burdge AH, Lewis-Jones S. Skin biopsy in general practice. BMF 1991;303:1179-80.

$8 \mathrm{Kahn} \mathrm{KL}$, Kosecoff J, Chassin MR, Solomon DH, Brook $\mathrm{RH}$. The use and misuse of upper gastrointestinal endoscopy. Ann Intern Med 1988;109:664-70.

9 Vaira D, Holton J, Osborn J, D'Anna L, Romanos A, Falzon M, et al. Endoscopy in dyspeptic patients: is gastric mucosal biopsy useful? Am $\mathcal{f}$ Gastroenterol 1990;85:701-4.

10 Williams B, Lukas M, Ellingham JHM, Dain A, Wicks ACB. Do young patients with dyspepsia need investigation? Lancet 1998;ii: 1349-51.

11 Goodman $H$. Interpretation of large intestinal mucosal biopsy specimens. Hum Pathol 1994;25:1150-8.

12 Bo-Lin GW, Vendrell DD, Lee E, Fordtran JS. An examination of microscopic colitis in patients with chronic diarrhoea. F Clin Invest 1985;75:1559-69.

13 Gledhill A, Cole FM. Significance of basement membrane thickening in the human colon. Gut 1984;25:1085-8.

4 Surawicz CM, Meisel JL, Yvisaker T, Saunders DR, Rubin CE. Rectal biopsy in the diagnosis of Crohn's disease: value of multiple biopsies and serial sectioning. Gastroenterology 1981;81:66-71.

15 Goodman MJ, Kirsner JB, Riddel RH. Usefulness of rectal biopsy in inflammatory bowel disease. Gastroenterology 1977;72:952-6.

16 Morson B, Pang L. Rectal biopsy as an aid to cancer control in ulcerative colitis. Gut 1967;8:423-34.

17 Saraga EP, Gardiol D, Costa J. Gastric dysplasia. A histological follow up study. Am $\mathcal{f}$ Surg Pathol 1987;11:788-96.

18 McBroom HM, Ramsay AD. The clinicopathological meeting. A means of auditing diagnostic performance. $A m \mathcal{F}$ Surg Pathol 1993;17:75-80. 